\title{
DAILY VAR FORECASTS WITH REALIZED VOLATILITY AND GARCH MODELS
}

In this paper we evaluate alternative volatility forecasting methods under Value at Risk (VaR) modelling. We calculate one-step-ahead forecasts of daily VaR for the WIG20 index quoted on the Warsaw Stock Exchange within the period from 2007 to 2011. Our analysis extends the existing research by broadening the class of the models, including both the GARCH class models based on daily data and models for realized volatility based on intraday returns (HAR-RV, HAR-RV-J and ARFIMA). We find that the VaR estimates obtained from the models for daily returns and realized volatility give comparable results. Both long memory features and asymmetry are found to improve the VaR forecasts. However, when loss functions are considered, the models based on daily data allow minimizing regulatory loss function, whereas the models based on realized volatility allow minimizing the opportunity cost of capital.

Keywords: VaR, intraday data, realized volatility, GARCH

DOI: $10.15611 /$ aoe.2015.1.06

\section{INTRODUCTION}

Volatility modelling is one of the most important concepts in financial econometrics associated with risk and uncertainty, and therefore it is central to asset pricing, portfolio management, option pricing, Value at Risk etc. Although directly unobservable, volatility is estimated with parametric and non-parametric methods as well as with data sampled at different frequencies. Traditionally the most popular method of estimating risk was to calculate variance, later on some parametric models for dynamic volatility estimation such as GARCH models or stochastic volatility models became popular. In recent years the access to databases with intraday financial instruments' prices has led to the development of a new class of methods that seem to be powerful in volatility estimation.

The idea of using intraday data in volatility estimation started in the early 1980s (Merton 1980), and was then developed in subsequent works (e.g. Taylor and Xu 1997). In the seminal paper, Andersen and Bollerslev (1998) introduced the concept of realized volatility (RV) as a new measure of risk.

\footnotetext{
* Poznań University of Economics
} 
They showed that volatility forecasts from the GARCH models are reasonable when compared to realized variance, calculated as the sum of squares of intradaily returns in a given day, instead of squares of daily returns usually used in that time. In fact there is a huge recent literature on the importance of realized variance as an ex-post benchmark to volatility forecasts from the GARCH models (Andersen and Bollerslev 1998, Doman 2003, Będowska-Sójka and Kliber 2009).

Nowadays, when estimating volatility one may choose between at least two possible solutions, based on daily or intradaily data. The application of intraday data always produces higher costs caused by gathering the data, requires a large amount of data handling and is limited to the assets for which data is available. However, intuitively the intradaily data contains more information. The use of daily data is much more convenient and cheaper, but probably not as informative. The question is, if information included in intraday data is useful for volatility modelling and forecasting.

Realized volatility itself is usually modelled with ARFIMA models (e.g. Andersen et al. 2003, Doman 2006, Fuertes and Olmo 2012), as well as the heterogeneous autoregressive realized variance models of Corsi (2009) (HAR-RV) and the extended HAR-RV-J and HAR-RV-CJ models incorporating jumps in the modelling process (e.g. Andersen et al. 2007). In the latter approach realized variance, which is a nonparametric measure of volatility, is modelled and forecasted with simple parametric models.

The aim of the paper is to compare the volatility forecasts obtained from the methods in which we use two different frequencies: daily data and equally sampled intradaily data. Volatility models are often used to characterize trading risk. Therefore we evaluate alternative forecasting methods under Value at Risk modelling as a natural application of volatility estimates (Giot, Laurent 2004). In the literature there is no clear answer as to which approach based on daily or intradaily data is better when estimating and forecasting volatility. Giot and Laurent (2004) indicated that in the case of stock indices and exchange rates an adequate ARCH-type model can deliver as accurate $\mathrm{VaR}$ forecasts as the models based on realized variance. They compared two GARCH class models, GARCH and APARCH with skewed $t$ distribution, to ARFIMA models for RV with skewed $t$ distribution. The forecasts are compared on the basis of the Kupiec (1995) and the Engle and Manganelli (2004) tests. Lunde and Hansen (2005) found no evidence that GARCH(1,1) is outperformed by more sophisticated models based on intraday data in an analysis of exchange rates, so they conclude that $\operatorname{GARCH}(1,1)$ beats other models based on intradaily data. McMillan et al. (2008) showed that the use of intraday data provides improved daily volatility and VaR forecasts relative to 
daily data and daily realized variance. Louzis et al. (2011) found that both the realized variance and the augmented GARCH models with the filtered historical simulation or the extreme value theory quantile estimation methods produce equally good VaR forecasts. Fuertes and Olmo (2012) found that the ARFIMA models produce better backtesting results than the GARCH models, but that the GARCH models prevail in terms of statistical verification. Louzis at al. (2013) used extended GARCH models and show that realized measures produce precise $\mathrm{VaR}$ forecasts.

In our paper we compare one-step ahead VaR forecasts from GARCH class models which are based on daily data and models that use RV calculated from intradaily returns. While the above cited papers show contrary results for different instruments and markets, there is still a gap in the literature concerning the Polish capital market, which is perceived as a fast-growing emerging market. Therefore we focus on the blue chip index, the WIG20, quoted on the Warsaw Stock Exchange.

In our research we consider the statistical and regulatory VaR performance evaluation methods. The question is which approach, based on daily or intradaily data, offers the better volatility forecast. The rest of the paper is as follows: in the next section competing volatility models used in the study are presented, in Section 2 the data are described, in Section 3 the Value at Risk is presented, and the methods of VaR evaluation are described. In Section 4 the empirical results are shown. The last section concludes.

\section{COMPETING VOLATILITY MODELS}

The aim of the paper is to compare the volatility forecasts from models based on daily data (GARCH class models) with models for volatility estimates based on intradaily data (realized variance). First, we characterize the GARCH models used in the study, then briefly describe the theoretical framework of the realized variance and present models used for modelling and forecasting RV.

\subsection{GARCH class models}

A popular approach in time-series analysis in order to capture heteroskedasticity and volatility clustering is the application of GARCH models. As proposed in the literature (e.g. Beck et al. 2001, McMillan and Speight 2007), we consider the simplest symmetric $\operatorname{GARCH}(p, q)$ model introduced by Engle (1982) and Bollerslev (1986). In our case it is specified for daily returns $r_{\mathrm{t}}$ in the following manner: 


$$
\begin{gathered}
r_{t}=\sigma_{t} \varepsilon_{t} \quad \varepsilon_{t} \sim \text { i.i.d. }(0,1) \\
\sigma_{t}^{2}=\omega+\sum_{q=1}^{Q} \alpha_{q} r_{t-q}^{2}+\sum_{p=1}^{P} \beta_{p} \sigma_{t-p}^{2} .
\end{gathered}
$$

We also consider the $\operatorname{IGARCH}(p, q)$ model as a representation that is close to RiskMetrics. This method was popularized by JP Morgan in 1996 and since then has been commonly used in the empirical research:

$$
\sigma_{t}^{2}=\omega+\sum_{p=1}^{P}\left(1-\beta_{p}\right) r_{t-p}^{2}+\sum_{p=1}^{P} \beta_{p} \sigma_{t-p}^{2}
$$

In order to capture asymmetry in volatility, we use the GJR-GARCH $(p, q)$ model with the specification of Glosten et al. (1993), where the leverage effect is represented by $\gamma$ parameters:

$$
\sigma_{t}^{2}=\omega+\sum_{q=1}^{Q} \alpha_{q}\left(r_{t-q}^{2}+\gamma_{q} I_{t-q} r_{t-q}^{2}\right)+\sum_{p=1}^{P} \beta_{p} \sigma_{t-p}^{2},
$$

where: $I_{t-q}=\left\{\begin{array}{l}1 ; \text { if } r_{t-q}<0 \\ 0 ; \text { if } r_{t-q} \geq 0\end{array}\right.$.

As long memory in volatility is one of the stylized facts quoted in the literature, the fourth model in this group is $\operatorname{FIGARCH}(p, d, q)$, that is capable of accommodating the persistence in volatility (Baillie et al. 1996):

$$
(1-L)^{d} \Phi(L) r_{t}^{2}=\omega+B(L)\left(r_{t}^{2}-\sigma_{t}^{2}\right)
$$

where $L$ is the backshift operator, $d$ is a fractionally integrated parameter, $0 \leq d \leq 1, \quad \Phi(L)=1-\sum_{i=1}^{q} \varphi_{i} L^{i}$ and $B(L)=1-\sum_{i=1}^{p} \beta_{i} L^{i}$. In a further estimation it is assumed that $\varepsilon_{t}$ is an i.i.d. process with Student $t$-distribution.

The forecasts of the conditional variance are obtained on the one-stepahead basis and used in Value at Risk forecasts backtesting procedure.

\subsection{Theoretical framework of realized variance and jumps}

We model realized variance as in the works of Andersen et al. (2003, 2007). The log price is assumed to follow a continuous time jump diffusion semi-martingale process: 


$$
d p(t)=\mu(t) d t+\sigma(t) d W(t)+\kappa(t) d q(t), \quad 0 \leq t \leq T
$$

where $p(t)$ is log price, $\mu(t)$ is continuous and locally bounded variation process, $W(t)$ is a standard Brownian motion, $\sigma(t)$ is strictly positive stochastic volatility process independent from $W(t), \kappa$ is a jump size and $q$ is a counting process with a value of 1 when there is a jump and 0 otherwise (Jajuga 2001, Laurent 2010).

The quadratic variation for cumulative return process is following (Andersen et al. 2007):

$$
[r, r]_{t}=\int_{t-1}^{t} \sigma^{2}(s) d s+\sum_{t-1<s \leq t} \kappa^{2}(s) .
$$

The integral $\int_{t-1}^{t} \sigma^{2}(s) d W(s)$ in equation (6) is called integrated variance, whereas the second part of the sum is describing the jump process.

In discretely sampled returns with $\Delta$ standing for the time that lasts between consecutive returns and $r(t) \equiv p(t)-p(t-\Delta)$, realized variance $R V_{t}(\Delta)$ is calculated by the summation of squared intradaily returns that are observed with given frequency:

$$
R V_{t}(\Delta)=\sum_{n=1}^{1 / \Delta} r_{t, n}^{2}
$$

As the sampling frequency of the return series increases, $\Delta \rightarrow 0$

$$
R V_{t}(\Delta) \rightarrow \int_{t-1}^{t} \sigma^{2}(s) d s+\sum_{t-1<s \leq t} \kappa^{2}(s)
$$

In the absence of jumps, realized variance will be a consistent estimator of integrated variance. This result is fundamental for modelling and forecasting realized variance (Andersen et al. 2003). However, as jumps are quite common in financial returns series, realized variance is not a robust estimator of integrated variance. Barndorff-Nielsen and Shephard (2004) introduced another measure called bipower variation which is a robust estimate of integrated variance. These two, realized variance and bipower variation $B V_{t}(\Delta)$, allow therefore estimating the jump component in the price process:

$$
R V_{t}(\Delta)-B V_{t}(\Delta) \rightarrow \sum_{t-1<s<t} \kappa^{2}(s) .
$$


In order to prevent the estimates of squared returns from being negative, Barndorff-Nielsen and Shephard (2004) truncated the measurement of jumps $J$ at zero:

$$
J_{t}=\max \left[R V_{t}(\Delta)-B V_{t}(\Delta), 0\right] .
$$

We will use equation (10) for calculating the jumps used in the HAR-RVJ model.

\subsection{Models for realized variance}

The realized variance is characterized by long memory (Andersen et al. $2001)$ and therefore is often modelled as ARFIMA $(m, \delta, s)$ processes that constitute a general class of dynamic processes. A realized variance series $R V=\left[R V_{1}, R V_{2}, \ldots, R V_{T}\right]$ follows an ARFIMA process if:

$$
\Phi(L)(1-L)^{\delta} R V_{t}=\Theta(L) \varepsilon_{t}
$$

where $L$ is the backshift operator, $\Phi(L)=\left(1-\Phi_{1} L-\Phi_{2} L^{2}-\ldots .-\Phi_{m} L^{m}\right)$ and $\Theta(L)=\left(1-\Theta_{1} L-\Theta_{2} L^{2}-\ldots .-\Theta_{s} L^{s}\right)$ are respectively the autoregressive and moving average polynomials in the lag operator $L,(1-L)^{\delta}$ is the fractional integration operator, $\delta$ is a fractional integration parameter and $\varepsilon_{t}$ is a stationary process. In the paper of Andersen et al. (2003) they found that the value of $\delta$ parameter is close to 0.4. In our paper the choice of an appropriate ARFIMA model is based on information criteria - finally we use the ARFIMA $(1, d, 0)$ model.

Another class of models that take into account the long memory feature is the HAR-RV models. In financial markets, either traders are perceived to be heterogeneous in the sense of a different horizon of investments (Muller et al. 2001), or information arrival is heterogeneous in nature (Andersen and Bollerslev 1998). This heterogeneity causes long memory in the series. Introduced by Corsi (2009), the heterogeneous autoregressive model of realized variance (HAR-RV) considers different volatility components and is therefore able to account for long memory and fat tails (Corsi 2009).

The model HAR-RV is the following (Corsi 2009):

$$
R V_{t+1}=\beta_{0}+\beta_{d} R V_{t}+\beta_{w} R V_{t}^{w}+\beta_{m} R V_{t}^{m}+\varepsilon_{t+1}
$$


where weekly $\left(R V_{t}^{w}\right)$ and monthly $\left(R V_{t}^{m}\right)$ volatility components are obtained as a simple average of daily quantities:

$$
\begin{gathered}
R V_{t}^{w}=\frac{1}{5}\left(R V_{t}^{d}+R V_{t-1 d}^{d}+\ldots+R V_{t-4 d}^{d}\right) \\
R V_{t}^{m}=\frac{1}{22}\left(R V_{t}^{d}+R V_{t-1 d}^{d}+\ldots+R V_{t-21 d}^{d}\right) .
\end{gathered}
$$

Andersen et al. (2007) considered the above model extended to jump components (HAR-RV-J) in the following way:

$$
R V_{t, t+1}=\beta_{0}+\beta_{d} R V_{t}+\beta_{w} R V_{t}^{w}+\beta_{m} R V_{t}^{m}+\beta_{j} J_{t}+\varepsilon_{t+1} .
$$

This class of models allows easily forecasting realized variance with ordinary least squares. The jumps introduced in the model come from equation (10).

\section{DATA DESCRIPTION}

In the literature evaluating VaR forecasts in the equity markets, probably the most extensively used financial series are from the NYSE or NASDAQ markets (e.g. Beck et al. 2013, Fuertes and Olmo 2012, Louzis, Xanthopoulos-Sisinis and Refenes 2011). There are also papers where VaR is calculated for financial instruments quoted on the Warsaw Stock Exchange (e.g. Pipien 2005, Piontek 2007). In extending the scope of previous research through the application and comparison of methods for data of different frequency, we use the daily and intradaily WIG20 index prices. The WIG20 index contains twenty blue chip companies quoted on the Warsaw Stock Exchange. On the basis of price data we calculated percentage logarithmic returns. The data sample starts on 4th of April, 2007, and ends on 21st of April, 2011 which gives altogether 1019 observations. The data come from www.stooq.pl.

We followed Andersen et al. (2007) suggestions to estimate RV as a sum of intraday squared returns where night returns are omitted. This approach is also motivated by the results of Fuertes and Olmo (2012), who found that night return does not improve the out-of-sample forecasts of VaR. In Figure 1 we present realized variance, RV, together with WIG20 returns. 


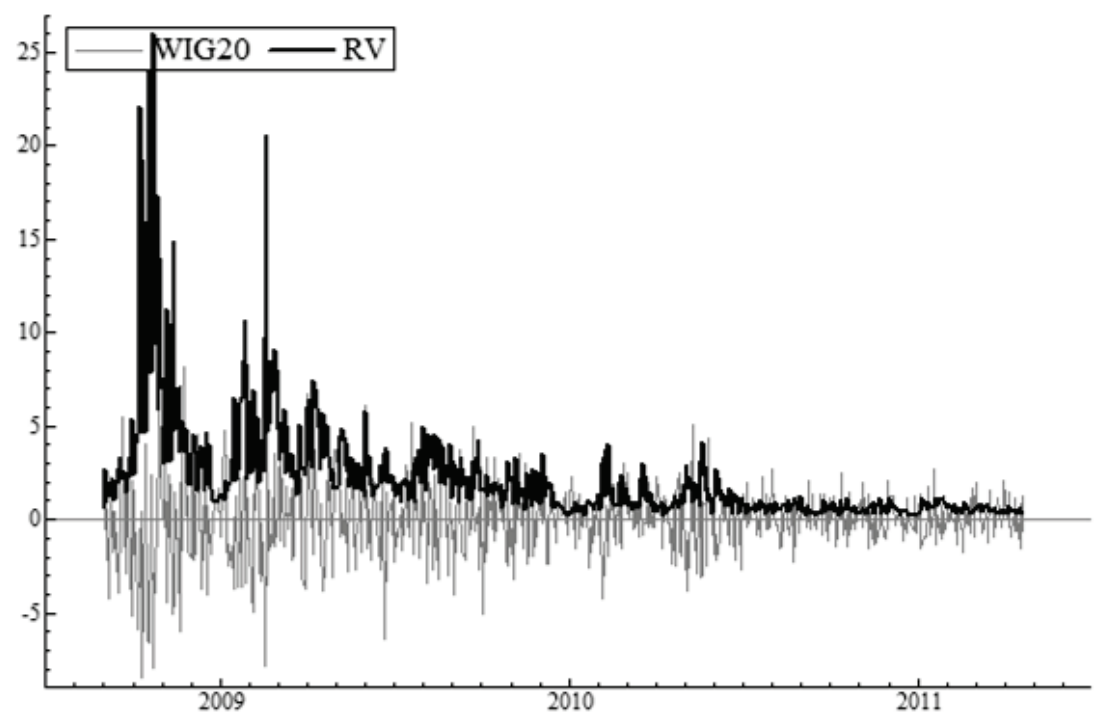

Figure 1. WIG20 returns, realized volatility and logarithm of realized variance.

When calculating realized variance, there is always a question of a proper frequency of returns. There is no single rule for that in the literature. Dacorogna et al. (1998) used hourly returns for realized variance, Corsi et al. (2009) suggested that for very liquid instruments (e.g. foreign exchange) the frequency of returns should be 20-30 minutes and for less liquid instruments an even lower frequency is recommended. Giot and Laurent (2004) used 5minute and 15-minute returns for stock market indices and show that both frequencies give similar results. Andersen et al. (2001) and Fuertes and Olmo (2012) used 5-minute returns, while Zumbach and Müller (2001) applied tick-by-tick data. As the WIG20 index consists of the most liquid stocks quoted on the Warsaw Stock Exchange, we focus on realized variance based on equally sampled 5-minute returns. Additionally, as the distribution of logarithm of realized variance is closer to normal than the distribution of realized variance, we consider the former in the study. For calculations we used Ox version 6.10 and G@RCH 6.1 (Laurent 2010).

\section{EVALUATING VALUE AT RISK PERFORMANCE}

Value at Risk quantifies the market risk of a portfolio to future market fluctuations (Sarma et al. 2004). Usually this is defined as the amount of money that might be lost within a given time horizon with a certain probability $\alpha$. 


$$
P\left(P_{t} \leq P_{t-1}-\operatorname{VaR}_{t}(\alpha)\right)=\alpha .
$$

In terms of returns, Value at Risk is usually defined as:

$$
P\left(r_{t} \leq-\operatorname{VaR}_{t}(\alpha)\right)=\alpha .
$$

Here in the paper we consider the conditional approaches that deliver forecasts for both tails of distribution in order to measure risk for long position and short position at the significance level $\alpha$. Assuming that $\Omega_{t-1}$ stands for information set at the time $t-1$, the left tail of distribution (long position) is defined as:

$$
P\left(r_{t} \leq-\operatorname{VaR}_{t}^{l}(\alpha) \mid \Omega_{t-1}\right)=\alpha
$$

whereas the right tail of distribution (short position) is defined as:

$$
P\left(r_{t} \geq \operatorname{VaR} R_{t}^{s}(\alpha) \Omega_{t-1}\right)=\alpha .
$$

In evaluating VaR performance, a huge number of methods has been proposed (Lopez 1999, Sarma et al. 2003, Pipień 2005, Piontek 2007). Sarma et al. (2003) used a two-stage model selection procedure. In the first stage, models are tested for statistical accuracy, whereas in the second, subjective loss functions are used. In the paper we use a similar procedure. As in Giot and Laurent (2004), we consider two tests: the Kupiec test (1995) and the Dynamic Quantile Test of Engle and Manganelli (2004). Additionally, as in Pipień (2005) and Piontek (2007), we calculated three loss functions. Below are described the tests and loss functions we used.

\subsection{The Kupiec Test (1995)}

The Kupiec test requires computing the empirical failure rate which is the fraction of excess returns under (for the long position) and over (for the short position) the forecasted one-day-ahead VaR. In the case of a correctly specified VaR, the fraction of failures $f$ is equal to the assumed number of failures which is identical with the significance level for $\mathrm{VaR}$.

$$
\begin{aligned}
& H_{0}: f=\alpha \\
& H_{1}: f \neq \alpha
\end{aligned}
$$


The test statistic is:

$$
L R=2\left(\ln \left(\left(\frac{N}{T}\right)^{N}\left(1-\frac{N}{T}\right)^{T-N}\right)-\ln \left(\alpha^{N}(1-\alpha)^{T-N}\right)\right) \sim \chi^{2}(1)
$$

where $N$ is the number of violations (failures) of the reported VaR, and $T$ is the number of observations.

\subsection{The Dynamic Quantile Test (Engle and Manganelli 2004)}

This test allows to examine if the present violations of the VaR measure are not correlated with the past violations. Let us denote an indicator function, $I_{t}(\alpha)$, that obtains the value of 1 in the case of $I_{t}\left(r_{t} \leq-\operatorname{VaR}_{t}^{l}(\alpha)\right)$ for a long position and $I_{t}\left(r_{t} \geq \operatorname{VaR}_{t}^{s}(\alpha)\right)$ for a short position, and zero otherwise. Engle and Manganelli (2004) proposed to use new variables:

$$
\begin{gathered}
\operatorname{Hit}_{t}^{l}(\alpha)=I_{t}\left(r_{t} \leq-\operatorname{VaR}_{t}^{l}(\alpha)\right)-\alpha \\
H_{i t}^{s}(\alpha)=I_{t}\left(r_{t} \geq-\operatorname{VaR}_{t}^{s}(\alpha)\right)-(1-\alpha)
\end{gathered}
$$

where subscripts $l$ and $s$ stand for long and short. The two hypotheses are tested jointly:

$$
H_{01}: E\left(H i t_{t}^{l}(\alpha)\right)=0\left(\text { or } E\left(H i t_{t}^{s}(\alpha)\right)=0\right)
$$

$H_{02}: \operatorname{Hit}_{t}^{l}(\alpha)$ (or $\left.\operatorname{Hit}_{t}^{s}(\alpha)\right)$ is uncorrelated with the variables included in the information set.

Testing both hypotheses can be done jointly within an artificial regression:

$$
\operatorname{Hit}_{t}(\alpha)=\mathbf{Z} \lambda+\varepsilon_{t}
$$

where $\mathbf{Z}$ is a $T \times k$ matrix with the first column consisting of ones, and the next $p$ columns consisting of past violations Hit $_{t-1}, \ldots, H_{t-p}$. In the $k-p-1$ remaining columns, additional independent variables are included (e.g. past returns, the squared past returns, VaR itself etc.). Engle and Manganelli (2004) showed that the test statistic DQT satisfies the following relation: $D Q T=\frac{\hat{\lambda}^{T} \mathbf{X}^{T} \mathbf{X} \hat{\lambda}}{\alpha(1-\alpha)} \sim \chi^{2}(k)$ where $\hat{\lambda}$ is OLS estimate of $\lambda$. 


\subsection{Loss Functions}

The idea of using the loss function in a VaR evaluation comes from Lopez (1999). Each loss function presented below reflects the different approach of the risk manager. Generally they are constructed in the way that they give higher scores when the failure occurs, but each of them takes into account the different utility functions of risk managers. The VaR model that minimizes the value of the loss functions is considered to be attractive.

The binomial loss function (BL) proposed by Lopez (1999) penalizes all failures equally:

$$
f_{t}^{B L}=\left\{\begin{array}{ll}
0, & r_{t}>\operatorname{VaR}_{t}(\alpha) \\
1, & r_{t} \leq-\operatorname{VaR}_{t}(\alpha)
\end{array} .\right.
$$

The regulatory loss function (RL) proposed by Sarma et al. (2003) reflects the regulator's utility function by paying attention to the magnitude of failures. It is constructed in the following way:

$$
f_{t}^{R L}=\left\{\begin{array}{ll}
0, & r_{t}>-\operatorname{VaR}_{t}(\alpha) \\
1+\left(r_{t}+\operatorname{VaR}_{t}(\alpha)\right)^{2}, & r_{t} \leq-\operatorname{VaR}_{t}(\alpha)
\end{array} .\right.
$$

The firm loss function (FL) penalizes failures, but at the same time takes into account the opportunity cost of capital (Sarma et al. 2003):

$$
f_{t}^{F L}= \begin{cases}c \cdot \operatorname{VaR}_{t}(\alpha), & r_{t}>-\operatorname{VaR}_{t}(\alpha) \\ 1+\left(r_{t+n}+\operatorname{VaR}_{t}\right)^{2}, & r_{t} \leq-\operatorname{VaR}_{t}(\alpha)\end{cases}
$$

where the constant $c$ measures the opportunity cost of capital. We assume that $c=1$.

\section{EMPIRICAL RESULTS}

The aim of the paper is to compare the accuracy of one-step ahead VaR forecasts from the GARCH class models based on daily data and models that incorporate realized variance, RV. First, we estimate models for daily returns data and RV data. In both approaches, based on daily and intradaily data, one-step-ahead forecasts of volatility are made from 2009.05.05. to 2011.04.21 (500 forecasts). Each model from those presented in Section 1 is re-estimated in a moving window on a daily basis with 519 observations used in the models' estimation. 
In Tables 1 and 2 we present the results of the Kupiec (1995) and the DQT Engle and Manganelli (2004) tests, as well as the loss functions (BL, RL, FL) respectively for the long and short position. For the long position, the Kupiec test rejects three GARCH class models at $\alpha=0.05$ and two of RV models at $\alpha=0.01$. In the case of the DQT test, only the GJR-GARCH model is not rejected at $\alpha=0.1$, whereas for $\alpha=0.05$ only the HAR model is rejected. For $\alpha=0.01$, the GARCH, IGARCH and FIGARCH models are rejected. In the next step, only the forecasts from the models that are not rejected by those tests are considered. For $\alpha=0.1$, there remains the GJR-GARCH model only, while in the case of $\alpha=0.05$ the GJR-GARCH

Table 1

Forecasting performance of Value at Risk for the WIG20 index from 2009.05.05 through to 2011.04.21 - long position

\begin{tabular}{|c|c|c|c|c|c|}
\hline & Kupiec & DQT & BL & RL & FL $(k=1)$ \\
\hline Model & p-values & p-values & \multicolumn{3}{|c|}{ LF values } \\
\hline \multicolumn{6}{|c|}{$\mathrm{alfa}=0.1$} \\
\hline GARCH & 0.0072 & 0.0087 & 33 & 75.5349 & 992.4995 \\
\hline GJR-GARCH & 0.1238 & 0.1881 & 40 & 86.1888 & 971.8784 \\
\hline IGARCH & 0.0187 & 0.0056 & 35 & 77.3041 & 995.7068 \\
\hline FIGARCH & 0.0043 & 0.0096 & 32 & 76.4291 & 1001.2041 \\
\hline HAR & 0.1674 & 0.0001 & 41 & 94.7508 & 932.0675 \\
\hline HAR_J & 0.1238 & 0.0006 & 40 & 92.1408 & 931.0289 \\
\hline ARFIMA & 0.1238 & 0.0051 & 40 & 86.4906 & 965.5161 \\
\hline \multicolumn{6}{|c|}{$\mathrm{alfa}=0.05$} \\
\hline GARCH & 0.0271 & 0.1296 & 15 & 35.1797 & 1287.4964 \\
\hline GJR-GARCH & 0.0822 & 0.3753 & 17 & 40.0943 & 1248.9959 \\
\hline IGARCH & 0.0271 & 0.1296 & 15 & 35.0499 & 1291.5429 \\
\hline FIGARCH & 0.0142 & 0.0540 & 14 & 37.0870 & 1287.4478 \\
\hline HAR & 0.6852 & 0.0324 & 27 & 61.5602 & 1089.6199 \\
\hline HAR J & 0.3192 & 0.2207 & 30 & 62.7846 & 1083.9021 \\
\hline ARFIMA & 0.2885 & 0.1612 & 20 & 49.5348 & 1142.8469 \\
\hline \multicolumn{6}{|c|}{$\mathrm{alfa}=0.01$} \\
\hline GARCH & 0.3315 & 0.0000 & 3 & 5.9314 & 1927.4565 \\
\hline GJR-GARCH & 0.3315 & 0.9636 & 3 & 8.3034 & 1834.7055 \\
\hline IGARCH & 0.3315 & 0.0000 & 3 & 5.8684 & 1944.9874 \\
\hline FIGARCH & 0.6414 & 0.0000 & 4 & 9.1125 & 1886.0971 \\
\hline HAR & 0.0077 & 0.1577 & 12 & 25.6395 & 1419.3939 \\
\hline HAR J & 0.0199 & 0.1350 & 11 & 23.6312 & 1417.1897 \\
\hline ARFIMA & 0.3966 & 0.1260 & 7 & 18.8999 & 1496.8498 \\
\hline
\end{tabular}

Note: $p$-values of tests (Kupiec 1995), DQT of Engle and Manganelli 2004) and value of loss functions (binomial BL, regulatory RL and firm FL loss functions) for VaR forecasts. 
model, the HAR-RV-J model and the ARFIMA model are taken into consideration. Whereas both binomial and regulatory loss functions indicate the GJR-GARCH model as the best one, the firm loss function suggests the ARFIMA model, followed by the HAR-RV-J model. For $\alpha=0.01$, only the GJR-GARCH model and the ARFIMA model are compared. Whereas both binomial and regulatory functions have the lowest value in the case of the VaR forecasts from the GJR-GARCH model, the minimum value of the firm loss function is observed for forecasts from the ARFIMA model. This result is similar to the one presented in Fuertes and Olmo (2012). The differences between loss functions based on forecasts from these two models are substantial.

Table 2

Forecasting performance of Value at Risk for the WIG20 index from 2009.05.05 through to 2011.04.21 - short position

\begin{tabular}{|c|c|c|c|c|c|}
\hline & Kupiec & DQT & BL & $\mathbf{R L}$ & FL $(k=1)$ \\
\hline Model & $p$-values & p-values & \multicolumn{3}{|c|}{ LF value } \\
\hline \multicolumn{6}{|c|}{$\mathrm{alfa}=0.1$} \\
\hline GARCH & 0.7642 & 0.1971 & 48 & 116.1794 & 987.9438 \\
\hline GJR-GARCH & 0.1471 & 0.1643 & 60 & 134.4512 & 926.6552 \\
\hline IGARCH & 1.0000 & 0.0562 & 50 & 116.6931 & 987.5746 \\
\hline FIGARCH & 0.7642 & 0.4418 & 48 & 111.6093 & 986.6236 \\
\hline HAR-RV & 0.5556 & 0.0788 & 54 & 121.7169 & 934.2006 \\
\hline HAR-RV-J & 0.3063 & 0.0707 & 57 & 127.5004 & 934.451 \\
\hline ARFIMA & 1.0000 & 0.2349 & 50 & 112.4397 & 973.4979 \\
\hline \multicolumn{6}{|c|}{ alfa $=0.05$} \\
\hline GARCH & 1.0000 & 0.5673 & 25 & 56.6272 & 1263.7540 \\
\hline GJR-GARCH & 0.3192 & 0.6425 & 30 & 65.5180 & 1180.7613 \\
\hline IGARCH & 0.8384 & 0.5135 & 26 & 56.2624 & 1266.1681 \\
\hline FIGARCH & 1.0000 & 0.7896 & 25 & 53.2485 & 1255.9212 \\
\hline HAR-RV & 0.0337 & 0.0695 & 36 & 76.9702 & 1086.0841 \\
\hline HAR-RV-J & 0.0337 & 0.0925 & 36 & 79.2975 & 1087.2787 \\
\hline ARFIMA & 0.0792 & 0.3681 & 34 & 71.4913 & 1133.5788 \\
\hline \multicolumn{6}{|c|}{ alfa $=0.01$} \\
\hline GARCH & 1.0000 & 0.9996 & 5 & 10.1795 & 1902.1420 \\
\hline GJR-GARCH & 0.3966 & 0.9807 & 7 & 14.4588 & 1762.3093 \\
\hline IGARCH & 1.0000 & 0.9996 & 5 & 9.2055 & 1918.6767 \\
\hline FIGARCH & 0.6414 & 0.9987 & 4 & 7.6099 & 1862.4444 \\
\hline HAR-RV & 0.0003 & 0.1394 & 15 & 27.9149 & 1412.3676 \\
\hline HAR-RV-J & 0.0003 & 0.1394 & 15 & 29.3342 & 1412.2694 \\
\hline ARFIMA & 0.0479 & 0.7171 & 10 & 22.9329 & 1491.5628 \\
\hline
\end{tabular}

Note: $p$-values of tests (Kupiec 1995) and DQT of Engle and Manganelli 2004) and value of loss functions (binomial BL, regulatory RL and firm FL loss functions) for VaR forecasts. 
For the short position, the Kupiec test rejects both the HAR-RV and HAR-RV-J models at $\alpha=0.05$ and $\alpha=0.01$, while the DQT test shows no autocorrelation in the models under consideration. When comparing the values of the loss functions, the results are different. For $\alpha=0.1$, the VaR forecasts from the FIGARCH model attain the lowest binominal loss function, the VaR forecasts from the GARCH model gain the lowest regulatory loss function, whereas the lowest firm loss function is observed for the VaR forecasts from the GJR-GARCH model. For $\alpha=0.05$, the lowest value of binomial function is observed in the case of the $\mathrm{VaR}$ forecasts from the GARCH and FIGARCH models, in the case of regulatory loss function the forecasts from the FIGARCH model have the best value, while for firm's loss function the ARFIMA model has the lowest value (both HAR-RV and HAR-RV-J with an even lower loss function value are rejected by the Kupiec test). When considering the significance level of $\alpha=0.01$, forecasts from the FIGARCH model allow obtaining lower economic losses both for binomial and regulatory loss functions, but again, when firm loss function is taken into account the lowest value of the function is accomplished for the VaR forecasts from the ARFIMA model.
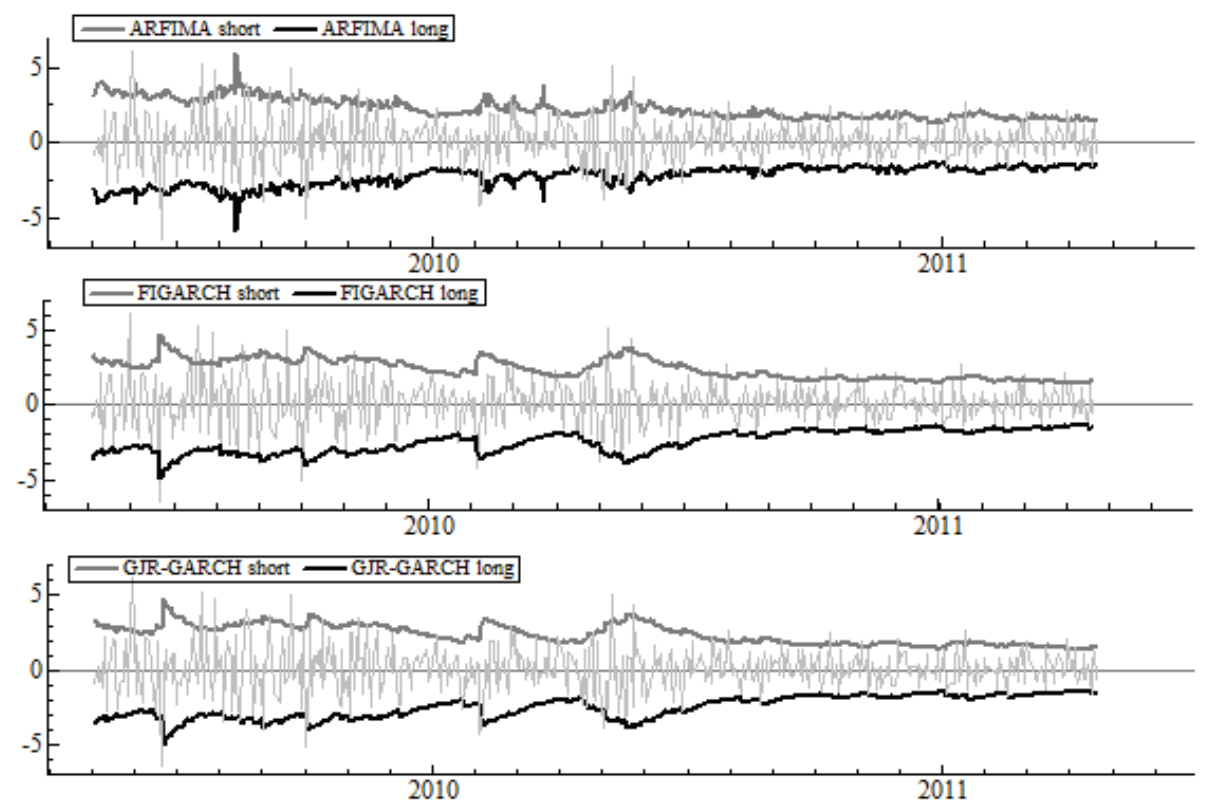

Figure 2. WIG20 returns and VaR forecasts at significance level $\alpha=0.05$ (GJR-GARCH, FIGARCH and ARFIMA models) 
Figure 2 presents the one-step-ahead forecasts of Value at Risk for the WIG20 index from the best models, the GJR-GARCH, FIGARCH and ARFIMA models, at $\alpha=0.05$ significance level for both short and long position. The forecasts within the GARCH class models are visually quite similar. However there is a clear distinction between the forecasts from the GARCH models and the ARFIMA model with the most noticeable differences observed in the periods when volatility switches from high to low level and in the opposite direction.

\section{CONCLUSION}

In the paper we consider the evaluation of alternative volatility forecasting methods for the purpose of VaR estimation and forecasts within a hectic crisis period. The forecasting performance of different models is compared in order to indicate the best one. We compare one-step ahead VaR forecasts from the GARCH class models which are based on daily data and models that use realized variance, RV, calculated from intradaily returns. We find that alternative VaR measures obtained from differently sampled data, give different VaR forecasts. When looking at statistical accuracy assessed by the Kupiec test or the Engle and Manganelli test, some VaR forecasts are rejected both when based on daily and intradaily data, leaving in some cases only a small number of models to be compared. Taking into account the VaR performance in the context of loss functions, when binomial and regulatory loss functions are considered, the VaR forecasts from daily data (especially the FIGARCH model) are better than those obtained from the models for RV, however if we look at the firm loss functions that measure the opportunity cost of capital faced by a firm, the models based on intradaily data give us better forecasts for both positions. In this sense the ARFIMA model generates superior VaR estimates in terms of capital efficiency, as this approach minimizes the opportunity cost of capital.

There is no clear solution as to which approach should be used when forecasting VaR. Based on the results of our study, the informational content of daily data seems to be sufficient to predict VaR properly, at least as far as the regulatory loss function is considered. The presented models based on intradaily data, however, open new fields in the search of the most effective VaR measures in the sense of firms' loss functions and opportunity cost of capital, even if the costs of gathering and handling the intradaily datasets are substantial. Our results illustrate the importance of the intraday approach in providing better forecasts of $\mathrm{VaR}$. 


\section{REFERENCES}

Andersen, T. G., Bollerslev, T., Diebold, F. X., Ebens, H., The Distribution of Realized Stock Return Volatility, "Journal of Financial Economics" 61, pp. 43-76, 2001.

Andersen, T. G., Bollerslev, T., Diebold, F. X., Labys, P., Modeling and Forecasting Realized Volatility, Econometrica 71, pp. 579-625, 2003.

Andersen, T. G., Bollerslev, T., Diebold, F.X., Roughing It Up: Including Jump Components in the Measurement, Modeling, and Forecasting of Returns Volatility, "The Review of Economics and Statistics" 89(4), pp. 701-720, 2007.

Andersen, T. G., Bollerslev, T., Answering the Skeptics. Yes, Standard Volatility Models Do Provide Accurate Forecasts, "International Economic Review" 39 (4), pp. 885-905, 1998.

Baillie, R., Bollerslev, T., Mikkelsen, H. O, Fractionally Integrated Generalized Autoregressive Conditional Heteroskedasticity, "Journal of Econometrics", 74, pp. 3-30, 1996.

Barndorff-Nielsen, O. E., Shephard, N., Econometric Analysis of Realised Volatility and Its Use in Estimating Stochastic Volatility Models, "Journal of the Royal Statistical Society", B, 64, pp. 253-280, 2002.

Beck, A., Kim, Y. S. I., Rachev, S., Feindt, M., Fabozzi, F., Empirical Analysis of ARMAGARCH Models in Market Risk Estimation on High-frequency US Data, "Studies in Nonlinear Dynamics and Econometrics" 17, 2, pp. 167-177, 2013.

Będowska-Sójka, B., Kliber, A., Realized Volatility Versus GARCH and Stochastic Volatility Models. The Evidence from the WIG20 Index and the EUR/PLN Foreign Exchange Market, "Przegląd Statystyczny", 57, 4, pp. 105-127, 2010.

Bollerslev, T., Generalized Autoregressive Conditional Heteroskedasticity, "Journal of Econometrics" 31, pp. 307-327, 1986.

Corsi, F, Dacorogna, M., Müller, U., Zumbach, G., High Frequency Data do Improve Volatility and Risk Estimation, FCO.2000-03-18, Olsen Ltd. Research Group, 2009.

Corsi, F., A Simple Approximate Long-memory Model of Realized Volatility, "Journal of Financial Econometrics" 7, No. 2, pp. 174-196, 2009.

Engle, R. F., Manganelli, S., CAViaR. Conditional Autoregressive Value at Risk by Regression Quantiles, "Journal of Business and Economic Statistics", 22, pp. 367-381, 2004.

Engle, R. F, Autoregressive Conditional Heteroscedasticity with Estimates of the Variance of United Kingdom Inflation, Econometrica 50, pp. 987-1007, 1982.

Fuertes, A-M., Izzeldin, M., Kalotychou, E., On Forecasting Daily Stock Volatility: The Role of Intraday Information and Market Conditions, "International Journal of Forecasting", 25(2), pp. 259-281, 2009.

Fuertes, A-M., Olmo, J., Exploiting Intraday and Overnight Price Variation for Daily VaR Prediction, "Frontiers in Finance and Economics" 9, 2, pp. 1-31, 2012.

Giot, P., Laurent, S., Modelling Daily Value-at-Risk Using Realized Volatility and ARCH Type Models, "Journal of Empirical Finance" 11,3, pp. 379-398, 2004.

Glosten, L. R., Jagannathan, R., Runkle, D. E., On The Relation between The Expected Value and The Volatility of Nominal Excess Return on Stocks, "Journal of Finance" 48, pp. 1779-1801, 1993. 
Jajuga, K., Ogólny model dynamiki cen finansowych, „Dynamiczne Modele Ekonometryczne", Toruń, pp. 7-14, 2001.

Kupiec, P., Techniques for Verifying the Accuracy of Risk Measurement Models, "Journal of Derivatives" 2, pp. 73-84, 1995.

Laurent, S., G@rch 6.0 help, Timberlake Consultants Ltd., London, 2010.

Lopez, J. A., Methods of Evaluating Value at Risk Estimates, Federal Reserve Bank of San Francisco Economic Review, pp. 3-17, 1999.

Louzis, D. P., Xanthopoulos-Sisinis, S., Refenes, A., Are Realized Volatility Models Good Candidates for Alternative VaR Prediction Strategies, http://mpra.ub.unimuenchen.de/30364/, 2011.

Louzis, D. P., Xanthopoulos-Sisinis, S., Refenes, A., The Role of High-Frequency Intra-daily Data, Daily Range and Implied Volatility in Multi-Period Value-at-Risk Forecasting, "Journal of Forecasting" 32, pp. 561-576, 2013.

Lunde, A., Hansen, P., A Forecast Comparison of Volatility Models: Does Anything Beat a GARCH(1,1)?, "Journal of Applied Econometrics", 20(7), pp. 873-889, 2005.

McMillan, D. G., Speight, A. E. H., Evans, K. P., How Useful is Intraday Data for Evaluating Daily Value-at-Risk?: Evidence from three Euro Rates, "Journal of Multinational Financial Management" 18, pp. 488-503, 2008.

McMillan, D. G., Speight, A. E. H., Value-at-Risk in Emerging Equity Markets: Comparative Evidence for Symmetric, Asymmetric, and Long-Memory GARCH Models, "International Review of Finance" 7, pp. 1-2, 2007

Merton, R., On Estimating the Expected Return on the Market; an Exploratory Investigation, "Journal of Financial Economics" 8, pp. 323-361, 1980.

Müller, U. A., Volatility Computed by Time Series Operators at High Frequency, Internal document UAM.1999-09-01, Olsen \& Associates, Zurich, 1999.

Piontek, K., Przegląd i porównanie metod oceny modeli VaR, Matematyczne i ekonometryczne metody oceny ryzyka finansowego, [in:] Chrzan, P., Prace Naukowe AE w Katowicach, Katowice, pp. 113-124, 2007.

Pipien, M., Wykorzystanie rozkładów predyktywnych w prognozie VaR i rezerw kapitałowych zwiazanych z ryzykiem rynkowym, "Dynamiczne Modele Ekonometryczne”, pp. 83-91, 2005.

Taylor, S., Xu, X., The Incremental Volatility Information in One Million Foreign Exchange Quotations, "Journal of Empirical Finance" 4, pp. 317-340, 1997.

Zumbach, G. O., Müller, U. A., Operators on Inhomogeneous Time Series, "International Journal of Theoretical and Applied Finance", 4(1), pp. 147-178, 2001.

Received: January 2013, revised: December 2014

Acknowledment: I would like to thank Krzysztof Piontek and two anonymous Referees for all valuable suggestions and comments. All remaining errors are mine. 